Marquette University

e-Publications@Marquette

$1-1-2006$

\title{
Factors Influencing girls' choice of Information Technology careers
}

Monica Adya

Marquette University, monica.adya@marquette.edu

Kate Kaiser

Marquette University, kate.kaiser@marquette.edu

Published version. "Factors Influencing Girls' Choice of Information Technology Careers," in Encyclopedia of Gender and Information Technology. Ed. Eileen M. Trauth. Hershey: IGI Global, 2006: 282-288. DOI. (C) 2006 IGI Global. Used with permission. 


\section{Factors Influencing Girls' Choice of Information Technology Careers}

Monica Adya

Marquette University, USA

Kate M. Kaiser

Marquette University, USA

\section{INTRODUCTION}

Many western nations have experienced declining numbers of women in the information technology (IT) workforce (Trauth, Nielsen, \& von Hellens, 2003). Between 1996 and 2002, women in the U.S. IT workforce declined from $41 \%$ to $34.9 \%$ (ITAA, 2003). This can hamper diversity and reduce the talent pool that can address needs of diverse endusers (Florida \& Gates, 2002). Why do women choose IT careers or reject them? Multidisciplinary research on career genderization reveals gender imbalance (Trauth, Nielsen, \& von Hellens, 2003). Career decisions against math, science, and technology (MST) are often made as early as age 11 without understanding long-term implications (AAUW, 2000). We examine influences on girls' choice of IT ca- reers, modeling social, structural, and personal variables that affect IT career choice.

Using Ahuja's (2002) classification of social and structural influences on women's IT careers, Beise, Myers, VanBrackle, and Chevli-Saroq's (2003) model of women's career decisions, and individual differences suggested by Trauth (2002), we extend literature to children and adolescents' career choices. Social influences bias internal and external gender perceptions and stereotyping, role models, peers, media, and family. Institutional support such as teachers and counselors, access to technology, and same-sex versus coeducational schools are structural influences. While both can influence career decisions, social factors have the most influence on children's early perceptions. Both factors can introduce gender-stereotyping effects on career choices.

Figure 1. Factors influencing girls' career choices

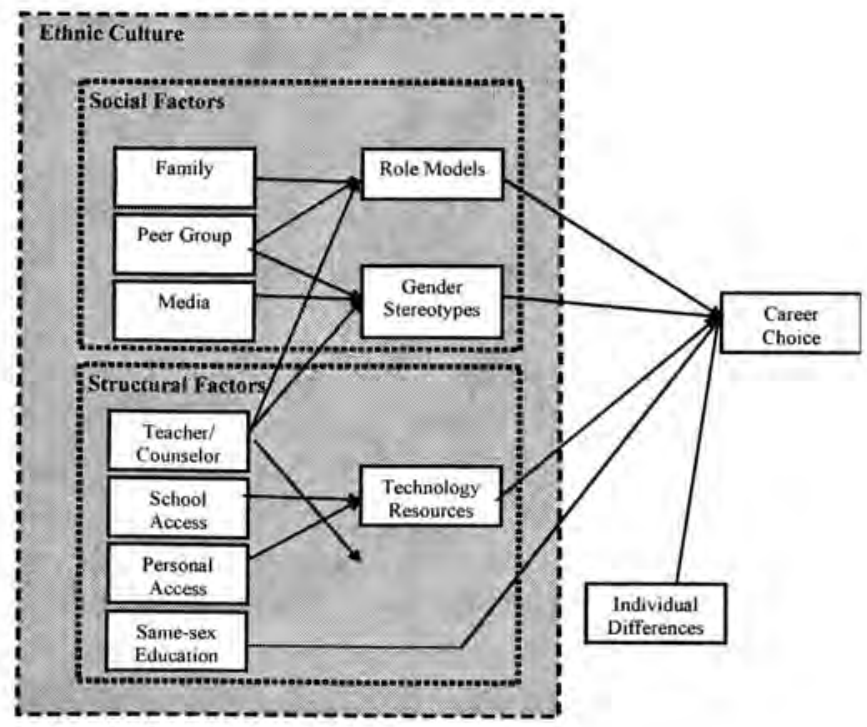


Gender stereotyping explains how girls perceive their role in society based on subtle societal cues. It can limit opportunities for both sexes. We also examine personality traits and external influences that make children unique. Their individual differences draw them to activities and content areas such as problem solving and interaction with people. Finally, ethnic culture can exert an influence on social and structural variables. Figure 1 from Adya and Kaiser (2005) presents our career choice model that is discussed in the next section.

\section{MAIN THRUST OF THE ARTICLE}

\section{SOCIAL INFLUENCES}

\section{Role Models}

Career choices are influenced by role models who are often familial or educational rather than famous societal figures (Dryler, 1998). Direct forms of parental influence, such as the degree to which students see their parents choosing IT careers or having contact with technology, are strong motivators to train for technical jobs. Family members can also motivate career choices indirectly by encouraging girls to pursue careers perceived to be "masculine."

Women entering male-dominated fields come from families where mothers have four year degrees, mothers are working, both parents are highly educated, and success is considered critical (Jackson, Gardner, \& Sullivan, 1993; Smith, 2000). Women choosing nontraditional careers recall fathers having a strong influence on career choices in nontraditional environments such as math, science, and technology (MST) (Gates, 2002; Trauth, 2002). Older brothers can influence girls toward "masculine" careers (Banks et al., 1992). Girls with only sisters chose careers that are more "feminine." Similar sibling influence is found for boys with male siblings.

Teenage peers have greater impact on social behaviors rather than career choices. During adolescence peer influence, particularly of boys on girls, impacts female self-concept, self-efficacy, classroom experiences, and external goal orientation. Such changes cause a clear demarcation between boys' and girls' career choices despite that girls score well on national level testing (Leslie, McClure,
\& Oaxaca, 1998). Among women, male peers play an important part in choice of MST as a career (Smith, 2000). Brekke (1997) on the other hand, attributes lack of participation in college-level physics to result partially from peer pressure that steers students away from MST.

\section{Media}

Media enhances gender stereotypes that emphasize physical image. Although girls interpret such images as unrealistic, they conform due to social pressure (Milkie, 1999). The few women shown in computer magazines, textbooks, and software are usually represented stereotypically $(\mathrm{Na}, 200 \mathrm{l})$. Media does not depict women in positions of power or as active computer users. Analysis of television advertising reports males with central, authoritative roles having more credibility than women regarding product knowledge. Women are shown against the backdrop of children $(\mathrm{Na}, 2001)$. Trade journals and media may have changed for young adult women showing them in professional roles but young teens do not read these. Seventeen and Cosmo Girl, the two most popular teen magazines, have little content that portrays women in technology careers.

\section{Gender Stereotypes}

Girls' perceptions of IT jobs may mirror stereotypes that do not represent the dynamic and rewarding nature of the field (von Hellens, Pringle, Nielsen, \& Greenhill, 2000). The Rhode Island Economic Policy Council (2000) reported that teenagers considered IT "uncool, nerdy, or boring." Steele (1997) found that gender stereotypes against female computer use negatively affected self-concept and career choices. Math has been stereotyped as masculine and is a critical filter that deters women from MST careers (Beise, Myers, VanBrackle, \& Chevli-Saroq, 2003).

Beliefs about role-appropriate behavior restrict choice of careers in college. Up to age ten, girls have similar subject interests as boys and are perceived to be better at all or most subjects than boys. As career choices form, girls begin narrowing their career options, often excluding MST (Miller \& Budd, 1999). These decisions are lifetime decisions that reduce opportunities to pursue technology careers. 
What causes gender-biased perceptions of technology careers? Parental, teacher, and peer role models can carry hidden messages about boys' and girls' capability with computers (Volman \& van Eck, 2001). Children whose parents have higher levels of education resist gender stereotyping while those whose parents have high school or less conform to gender stereotypes (Bouchard \& St-Amant, 2000). Parents with stereotypical math perceptions impact girls' self-perceptions about their math ability and success.

\section{STRUCTURAL FACTORS}

Structural factors represent institutional support available to women to pursue careers. The role of teachers and counselors in exposing students to technology, access to computer technology both at home as well as in schools, and the nature of the school environment can influence genderization or neutralization of IT careers.

\section{Teacher/Counselor Influences}

Research uncovers negative influences of teachers and counselors on MST career choices reflecting a gender bias in directing girls towards traditional careers (Gates, 2002; Turner, Brent, \& Pecora, 2002). However, women who moved from non-IT to IT careers indicated male professors as a strong influence (Canes \& Rosen, 1995). Teachers stereotype roles by giving the impression that boys are inherently better with computers than girls. Teachers, both male and female, attribute certain expertise to boys and give them priority for computer use (Volman \& van Eck, 2001).

Counselors devote little time on occupational and job counseling, ranking it fifth out of eight functions they typically perform (NCES, 2003). Since only $29 \%$ of girls receive support from career counselors, the amount of counseling is minimal. Moreover, middle and high school teachers and counselors are more comfortable advising toward traditional fields possibly because they lack IT background (Freeman \& Aspray, 1999).

\section{School Technology}

Women IT professionals cite school access to computers as a prominent reason for interest in IT
(Turner, Brent, \& Pecora, 2002). School computer access has increased significantly but reports on gender differences in its use have been mixed. Durndell \& Thomson (1997) report that differences in use of computers at school are non-existent or declining. Huber \& Schofield (1998) observe more frequent and diverse use of computers by boys than girls.

Only $60 \%$ of teachers reported using computers for instruction, $41 \%$ assigned computer tasks, while $23 \%$ felt prepared to use computers and the Internet (NCES, 2000). Teachers who felt technologically prepared were more likely to use technology in class and assign materials requiring computers for problem solving and data analysis. The current generation of teachers, while knowledgeable about computer use for personal productivity, may have limited knowledge about IT career choices.

\section{Home Technology}

Boys use home computers more frequently than girls and are more likely to own computers or be prominent users of shared computers (Harris, 1999). They use computers more than girls as a social activity (Durndell \& Thomson, 1997). Boys demand more power and functionality from home computers (Habib \& Cronford, 2002). Students with home computers have significantly more positive attitudes towards IT in college (Selwyn, 1998).

Perceived usefulness and attitudes about computers are key determinants of IT usage intention and behaviors (Venkatesh \& Davis, 2000). While increased technology access familiarizes children with computers, nature of use may influence beliefs and attitudes about technological careers. Although gender gap in technology access is non-existent, use of computers and the Internet is not. Boys use the Internet for a wider range of activities such as games, shopping, and finding information while girls restrict Internet use largely for e-mail and access to educational resources (NCES, 2002). Women exposed to play and collaboration-based assignments in training are more likely to choose MST careers (Smith, 2000).

\section{Same-Sex vs. Co-Educational Schools}

Sex-segregated environments inadvertently reinforce gender stereotypes, squander opportunities to 
address gender inequity, and expose students to teasing from peers in co-educational classes (Viadero, 2001). School environment has no impact on senior students from public schools with regard to math (Vezeau, Bouffard, \& Chouinard, 2000). Students attending same-sex high schools have minimal pressures from the opposite sex and have a better sense of belonging (Brutsaert \& Van Houtte, 2002; Watson, Quatman, \& Eder, 2002). If high school experiences reinforce notions that boys adapt better to technical areas, same-sex students have no comparisons (Jackson, 2002). One might expect that students of same-sex schools would not embrace gender-specific career choices. Although structural factors may exert similar influences in same-sex and co-educational schools, peers may impact differently.

\section{INDIVIDUAL DIFFERENCES}

An emerging theory that challenges the essentialist (Venkatesh \& Morris, 2000) and social construction (Adam, 2002) perspectives of gender and IT suggests that individual differences play an important role in forming career choices (Trauth, Quesenberry, \& Morgan, 2004), It suggests that the socio-cultural environment of women shapes their individual responses and experiences as IT professionals. Many individual differences are split along gender lines (Trusty, Robinson, Plata, \& Ng, 2000). Personality traits, enjoyment of computers, and overall outlook are some characteristics accounting for these differences. Women in IT reported several personality characteristics that made them different-powerful, forthright, strong, ambitious, driven, mathematical, logical, and less social than other girls (Trauth, 2002). Although female students enjoy using computers less than male students and perceive more problems with software, IT career women report higher levels of enjoyment with computers (Turner, Brent, \& Pecora, 2002). Such factors may impact occupational choices at young ages.

\section{ETHNIC CULTURE}

The under-representation of women in the IT workforce is global but appears more severe in developed nations (Trauth, Nielsen, \& von Hellens 2003). These studies find that women from India and China have more positive attitudes towards MST careers. Although both India and China represent similar economic environments, they represent a broad population that excels in MST careers. While market demands shape workforce trends, ethnic culture may provide more positive MST career orientations to women in these countries (Trauth, 2002). The lack of research suggests that crosscultural examination of structural and social factors requires further investigation.

\section{FUTURE TRENDS}

Three decades of research may not reflect how IT pervades homes and schools today. Home computer use is equally divided between male and female users (NCES, 2002). Technology is being increasingly integrated in school curriculum and education and the popularity of Internet gaming and instant messaging can reduce a gender-based digital divide (Gorriz \& Medina, 2000). Increasing number of women in the overall workforce and the knowledge that technical education is critical to success are other social trends that can promote the need for technology education.

Offshore software development in some countries emphasizes IT more than before. The U.S. is projected to face a shortage of 2 million IT professionals by 2006 but not enough students are graduating to fill this gap (O'Hara, 2000). India's emphasis on quality and its strong educational system has encouraged unprecedented software growth (West \& Bogumil, 2001). Such market changes make IT a very attractive career, which in turn can affect families' work habits, education, and interactions. Will these trends make IT a more attractive field to the next generation?

\section{CONCLUSION}

Declining numbers of women enrolled in IT curricula and the workforce should motivate IT educators and policymakers to improve programs conducive to technology careers. Before teachers can provide gender-neutral counseling, they themselves need 
training in technology and its career options. Teachers and counselors can benefit from increased interaction with industry and universities as well as ongoing technological training.

Parental involvement clearly has a positive bearing on choice of IT as a career. As fathers continue to influence girls' career choices and mothers get involved in the workforce, educating parents about IT career options is important. The misperception of what IT professionals do and what skills they need to succeed can deter many college students from choosing IT. Improved marketing may alter these misperceptions. The technological outlook today is changing for the better. If we can successfully identify and manage student IT career perceptions during adolescence, women may increasingly populate the IT workforce and college level programs.

\section{REFERENCES}

AAUW. (2000). Tech-savvy: Educating girls in the new computer age. AAUW, Washington, DC.

Adam, A. (2002). Exploring the gender question in critical information systems. Journal of Information Technology, 17(2), 59-67.

Adya, M., \& Kaiser, K. M. (2005). Early determinants of women in the IT workforce: A model of girl's career choices. Forthcoming. Information Technology \& People.

Ahuja, M. K. (2002). Women in the information technology profession: A literature review, synthesis, and research agenda. European Journal of Information Systems, 11(1), 20-34.

Banks, M., Bates, I., Breakwell, G., Bynner, J., Emler, N., Jameson, L., et al. (1995). Careers and identities. Philadelphia: University Press.

Beise, C., Myers, M., VanBrackle, L., \& ChevliSaroq, N. (2003). An examination of age, race, and sex as predictors of success in the first programming course. Journal of Informatics Education Research, 5(1), 51-64.

Bouchard, P., \& St-Amant, J. C. (2000). Gender identities and school success. Alberta Journal of Educational Research, 46(3), 280-284.
Brekke, S. E. (1997). Physics classes, career choices, and inner-city schools. The Physics Teacher, 35(8), 512 .

Brutsaert, H, \& Van Houtte, M. (2002). Girls' and boys' sense of belonging in single-sex vs. co-educational schools. Research in Education, 68, 48-56.

Canes, B. J., \& Rosen, H. S. (1995). Following in her footsteps? Faculty gender composition and women's choices of college majors. Industrial \& Labor Relations Review, 48(3), 486-505.

Dryler, H. (1998). Parental role models, gender, and educational choice. British Journal of Sociology, 49(3), 375-398.

Durndell, A., \& Thomson, K. (1997). Gender and computing: a decade of change? Computers and Education, 28(1), 1-9.

Florida, R., \& Gates, G. (2002). Technology and tolerance: The importance of diversity of high technology growth, Survey Series. The Brookings Institution, 1-12. Retrieved June 20, 2005, from http:/ /www.brook.edu/dybdocroot/es/urban/techtol.pdf

Freeman, P., \& Aspray, W. (1999). The supply of information technology workers in the United States. Computing Research Association. Retrieved June 20,2005 , from, http://www.cra.org/reports/ wits/cra.wits.html

Gates, J. (2002). Women's career influences in traditional and non-traditional fields. Poster presented at the Biennial meeting of the Society for Research in Adolescence. New Orleans, L.A.

Gorriz, C. M., \& Medina, C. (2000). Engaging girls with computers through software games. Communications of the ACM, 43(1), 42-50.

Habib, L., \& Cronford, T. (2002). Computers in the home: Domestication and gender. Information Technology \& People, 15(2), 159-174.

Harris, S. (1999). Secondary school students' use of computers at home. British Journal of Educational Technology, 30(4), 331-339.

Huber, B. R., \& Schofield, J. W. (1998). Gender and the sociocultural context of computing in Costa Rica. In H. Bromley \& M. W. Apple (Eds.), Educa- 
tion/technology/power: Educational computing as a social practice (pp. 103-132). Albany: State University of New York Press.

Information Technology Association of America (ITAA). (2003). ITAA Report of the Blue Ribbon Panel on IT Diversity, Information Technology Association of America. Retrieved February 9, 2005, from http://www.itaa.org/workforce/docs/03 divreport.pdf

Jackson, C. (2002), Can single-sex classes in coeducational schools enhance the learning experiences of girls and/or boys? An exploration of pupils' perceptions. British Journal of Educational Research, 28(1), 37-48.

Jackson, L. A., Gardner, P. D., \& Sullivan, L. A. (1993). Engineering persistence: Past, present, and future factors and gender differences. Higher Education, 26, 227-246.

Leslie, L. L., McCLure, G. T., \& Oaxaca, R. L. (1998). Women and minorities in science and engineering: A life sequence analysis. The Journal of Higher Education, 69(3), 239-276.

Milkie, M. A. (1999). Social comparisons, reflected appraisals, and mass media: The impact of pervasive beauty images on black and white girls' self-concept. Social Psychology Quarterly, 62(2), 190210.

Miller, L., \& Budd, J. (1999). The development of occupational sex-role stereotypes, occupational preferences, and academic subject preferences in children at ages 8, 12, and 16. Educational Psychology, 19(1), 17-35.

Na, M. (2001). The cultural construction of the computer as a masculine technology: An analysis of computer advertisements in Korea. Asian Journal of Women's Studies, 7(3), 93-114.

National Center for Education Statistics (NCES). (2000). Teachers tools for the $21^{\text {st }}$ century: $A$ report on teacher's use of technology. Education Public Center (ED Pubs), Jessup, MD.

National Center for Education Statistics (NCES). (2002). Digest of education statistics, 2002. Washington DC. Retrieved February 9, 2005, from http:/ /nces.ed.gov/programs/digest/d02/index.asp
National Center for Education Statistics (NCES). (2003). High school guidance counseling, Education Public Center (ED Pubs), Jessup, MD. Retrieved February 9, 2005, from http://www.nces. ed.gov/pubsearch/pubsinfo.asp?pubid $=2003015$

O'Hara, C. (2000, June 9). Survey confirms IT staffing woes. Computerworld.Retrieved June 20, 2005, from http://www.computerworld.com.au/ index.php/id;328974092;fp;512;fpid;1572120019

Rhode Island Economic Policy Council. (2000). What Rhode Island teens think of information technology careers. Rhode Island Economic Policy Council. Retrieved June 20, 2005, from http://www. ripolicy.org/resources/content/FocusGrpTeens.pdf

Selwyn, N. (1998). The effect of using a home computer on students' educational use of IT. Computers and Education, 31(2), 211-227.

Smith, L. B. (2000). The socialization of females with regard to a technology-related career: recommendation for change. Meridian: A Middle School Computer Technologies Journal, 3(2). Retrieved June 20, 2005, from http://www.ncsu.edu/meridian/ sum2000/career/index.html

Steele, M. (1997). Using music to increase interest in computers for girls and minorities. Teaching and Change, 4(4), 293-312.

Trauth, E.(2002). Odd girlout: An individual differences perspective on women in the IT profession. Information Technology \& People, 15(2), 98-118.

Trauth, E. M., Nielsen, S. H., \& von Hellens, L. A. (2003). Explaining the IT gender gap: Australian stories for the new millennium. Journal of Research and Practice in Information Technology, 35(1), 7-20.

Trauth, E. M., Quesenberry, J. L., \& Morgan, A. J. (2004). Understanding the under-representation of women in IT: Toward a theory of individual differences. In S. Weisband (Ed.), Proceedings of the 2004 ACM SIG MIS CPR Conference. Association for Computing Machinery, Tucson, AZ.

Trusty, J., Robinson, C. R., Plata, M., \& Ng, K. (2000). Effects of gender, socioeconomic status, and early academic performance on postsecondary 


\title{
Factors that Influence Women and Men to Enroll in IT Majors
}

\author{
Claire R. McInerney \\ Rutgers, The State University of New Jersey, USA
}

\section{INTRODUCTION}

Because of the ubiquitous nature of information technology, there is a continuous need for IT professionals. There has been a steady growth in the information technology industry as well as an increase in the use of information technology. However, the number of qualified technology workers has not kept up with the demand for technologyskilled labor. One reason for the workforce shortage is that women are underrepresented. Not only are there many fewer women in the IT workforce, but there are fewer women entering and graduating from traditional technology-related academic programs like computer science (CS), computer engineering (CE), and systems science. In 1986, approximately $36 \%$ of the U.S. graduates in CS and CE were women; in 2004, $17 \%$ were women (Bryant \& Irwin, 2001; Carver, 1999; Zweben, 2005). Of those earning doctoral degrees in 2004 only $18 \%$ were women (Zweben, 2005). Given that $51 \%$ of the total population is women, these statistics give a vivid explanation of why there is a shortage of IT workers.

\section{BACKGROUND}

In the United States in 1999, four core IT occupations-computer scientists, computer engineers, systems analysts, and programmers-employed over 2.2 million people (United Engineering Foundation, 1999). In 2004, only $0.3 \%$ of incoming freshman college women and $2.8 \%$ of men expressed an interest in majoring in computer science, according to the Higher Education Research Institute (n.d.). The numbers of students interested in engineering are also down despite U.S. Commerce Department reports that show $70.2 \%$ of all vacant positions in science and engineering between 2002 and 2012 (a total of 1.6 million jobs) will be in information technology. All programmers and others who work in IT professions do not have university degrees; however, education remains a critical factor in preparing the IT workforce. In 2002, the number of students pursuing doctorates in computer science in the top 50 U.S. research universities fell to the lowest number in 12 years (Foster, 2005).

The small (and declining) numbers of women enrolling in IT-related degree programs in universities should be a cause of concern (Kossuth \& LegerHornby, 2004). Parents of daughters might be concerned because high-paying IT jobs are not available to young women without academic credentials. Industry managers could be concerned that the underused potential of women professionals limits needed skills in the IT workplace such as organizational expertise, an understanding of customer service, and the ability to work collaboratively. With inadequate preparation for the IT field, women can miss out on opportunities for creative work, the chance to influence the IT field, and professional work that can be financially rewarding.

With limited numbers of women in positions in which software is being created, the female perspective in software products will be underrepresented. The consequence is that girls and young women may be less interested in the field of technology because the software, games, technology products, and so forth do not appeal to them.

\section{FACTORS THAT INFLUENCE ENROLLMENT IN IT MAJORS}

\section{Career Interest}

Although it is fairly common today to have more than one career in a lifetime, the choice of a university discipline and the subsequent career is one of the 